\title{
Habilidades e competências desejáveis aos profissionais de inteligência competitiva
}

Paulo Oliveira

Mestre em engenharia de produção, na linha de pesquisa competitividade e estratégias empresariais (UFMG).

Doutorando em ciência da informação na UFMG.

E-mail:phdic@yahoo.com.br

Juarez Lacerda

Mestre em tecnologia - manufatura integrada por computador. E-mail: cp1y-adm2006@yahoo.com.br

\section{Resumo}

Neste artigo, são analisadas as principais habilidades e competências desejáveis aos profissionais de IC a partir de uma cuidadosa revisão de literatura, tomando como referência as etapas do ciclo de IC e os estudos de Robert $L$. Katz sobre habilidades gerenciais. Os resultados demonstram que as habilidades e competências dos profissionais de IC tendem a variar conforme as etapas do ciclo de IC em que estes profissionais estejam envolvidos.

\section{Palavras-chave}

Ciclo de IC. Habilidades e competências. Profissionais de IC.

Desirable skills and abilities for professionals of competitive intelligence

\begin{abstract}
In this article, the main and desired abilities of IC professionals are outlined based literature review, taking into consideration the cycle stages of IC and the studies by Robert L. Katz on managerial abilities. The results show that the skills and competencies of IC professionals may vary according to the IC cycle stages they might be involved in.
\end{abstract}

\section{Keywords}

Cycle of IC. Skills and abilities. Professionals of IC.

\section{INTRODUÇÃO}

O tema inteligência competitiva (IC) vem se consolidando no Brasil e no mundo nas últimas décadas como prática gerencial indispensável ao sucesso empresarial. Uma pesquisa realizada pela Global Intelligence Alliance em 2007 com 181 empresas localizadas em nove países, dentre eles o Brasil, demonstra a intenção das empresas em expandir as suas práticas de IC. As empresas estão cada vez mais preocupadas em monitorar os movimentos dos seus competidores atuais e futuros e, para isso, têm investido em infra-estrutura de IC e no treinamento e desenvolvimento dos seus profissionais de IC em captação, interpretação e disseminação de produtos de inteligência sobre os seus ambientes competitivos.

A intenção de aplicar as melhores práticas de IC no mundo dos negócios tem trazido grandes contribuições e desafios para as organizações e para os profissionais envolvidos diretamente com as práticas de IC. Para as organizações, o desafio da busca constante por melhores produtos e serviços faz com que elas se preocupem cada vez mais com a melhoria contínua de seus processos, estejam eles nos níveis estratégico, tático ou operacional. Essa preocupação favorece o aumento na capacidade produtiva e competitiva das empresas nos mercados onde atuam, possibilitando melhoria na qualidade de seus produtos e serviços, além de uma preocupação contínua na modernização de seus processos internos e no desenvolvimento de seus recursos humanos.

Para Porter (1998), empresas que não conseguem se impor no atual contexto competitivo estão fadadas ao desaparecimento. Nesta mesma linha de raciocínio, D'Aveni (1995) complementa afirmando que a competição está em toda a parte, não apenas nos segmentos industriais de alta tecnologia e de rápido crescimento, mas em todos os segmentos, até nos ambientes mais estáveis e calmos. Para ele, existem poucos segmentos industriais e poucas empresas que tenham escapado dessa mudança no ambiente competitivo. Hope e Hope (2002) apostam na ascensão do conhecimento como o principal recurso para alavancar o potencial competitivo das organizações na terceira onda, ou seja, na era da informação.

Neste sentido, o aumento da concorrência, proporcionado pelo processo da globalização, pelos 
avanços tecnológicos e pela onda de fusões e aquisições que assolaram o mundo nas últimas décadas, tem gerado a necessidade de as organizações manterem as melhores práticas de IC e criado um cenário propício para debater as habilidades e competências desejadas aos profissionais de IC nesse início de milênio. Para esses profissionais, o aumento da concorrência tem gerado desafios e oportunidades. Muitas empresas estão se voltando para a IC como ferramenta gerencial estratégica e investindo na criação de centros e processos sistematizados de IC, o que tem gerado muitas oportunidades de trabalho e de crescimento profissional. Assim, o presente estudo busca descrever as principais habilidades e competências necessárias a esses profissionais no atual contexto competitivo por que passam as organizações contemporâneas e classificá-las em três grandes grupos (humanas, técnicas e conceituais) tomando como referência as fases do ciclo da IC e o estudo sobre habilidades gerenciais publicado por Robert L. Katz na Harvard Business Review em 1974. Não se pretende neste artigo esgotar completamente o tema, mas trazer à tona a importância de considerar as pessoas, em especial os profissionais de IC, como elementos-chave no atual contexto competitivo por que passam as organizações contemporâneas.

\section{O CICLO DA INTELIGÊNCIA COMPETITIVA}

Autores como Fuld (1995), Kahaner (1996), Tarapanoff (2001), Miller (2002), Precott e Miller (2002) e Choo (2003), dentre outros, têm analisado a importância da gestão do conhecimento e a necessidade de as organizações desenvolverem processos sistemáticos de coleta, análise e disseminação de informações estratégicas (inteligência) para os tomadores de decisões como instrumento potencializador das atividades de geração de vantagens competitivas sustentáveis e duradouras. $\mathrm{O}$ uso da inteligência nos negócios deve propiciar as condições necessárias para que as organizações consigam antecipar o futuro e a movimentação de seus competidores, além de favorecer o uso de estratégias competitivas mais eficazes.

Em termos conceituais, a Associação Brasileira dos Analistas de Inteligência Competitiva (ABRAIC, 2007) define a IC como "a atividade de inteligência voltada para o mundo dos negócios, ou seja, para o ambiente competitivo. Busca a manutenção ou o desenvolvimento de vantagens competitivas em relação aos concorrentes". Tarapanoff (2001, p.45) complementa esta definição afirmando que "para ter inteligência é preciso contar com uma infra-estrutura de telecomunicações como base, utilizar computadores e softwares e gerar conteúdos informacionais, em forma de base de dados, produtos e serviços". Assim, composta de diversos tipos de informação, a inteligência competitiva é um processo sistemático que transforma dados esparsos em conhecimento estratégico (TARAPANOFF, 2001). Desta forma, uma organização é inteligente quando ela identifica, captura, disponibiliza e usa de forma extensiva a informação e o conhecimento (CHOO, 2003).

Os estudos sobre as práticas de IC têm ganhado força entre os empresários nesses últimos anos. Segundo Miller (2002), as práticas de IC podem ser descritas a partir de um conjunto de quatro fases principais: (1) levantamento de necessidades de inteligência e dos responsáveis pela tomada de decisão estratégica; (2) coleta de dados e informações; (3) análise das informações (geração de produtos de inteligência); (4) disseminação dos produtos de inteligência gerada aos responsáveis pelas decisões. $\mathrm{Na}$ primeira fase, a atividade principal volta-se para dois aspectos importantes: (a) identificar os usuários da inteligência e as respectivas necessidades. Nesta fase, também chamada de planejamento, é comum a utilização da ferramenta 5W1H (What, Who, Where, When, Why e How), porque ela fornece as perguntas básicas que orientarão todas as demais fases do ciclo de IC. Algumas perguntas podem ser feitas aos tomadores de decisão, conforme apresentado no quadro 1.

$\mathrm{Na}$ fase de coleta de dados propriamente dita, os responsáveis devem buscar informações relevantes para a organização a partir de um roteiro previamente definido. Pode-se utilizar dois tipos de fontes

\section{QUADRO 1}

O uso da ferramenta $5 \mathrm{~W} 1 \mathrm{H}$ na fase de planejamento do processo de IC

1. Quais decisões precisam ser tomadas?

2. O quê os decisores já sabem ou precisam saber?

3. Por que os decisores precisam dessa informação analisada?

4. Quando os decisores precisam dessa informação analisada?

5. O que os decisores farão com a inteligência produzida e disponibilizada?

6. Qual o custo de obter a inteligência solicitada?

7. Qual o custo de não obter a inteligência solicitada?

8. Como os decisores preferem que a inteligência produzida seja repassada?

Fonte: adaptado de Tarapanoff (2001) e Miller e Prescott (2002). 
principais: (1) fontes primárias - experts como analistas, consultores, colunistas; consumidores, fornecedores e pessoal interno qualificado para ceder essas informações e/ou (2) fontes secundárias impressas e eletrônicas como banco de dados comerciais e publicações periódicas - relatórios de analistas, publicações governamentais, relatórios setoriais, discursos de executivos, relatórios técnicos e relatórios sobre patentes. Segundo Miller (2002:37), normalmente os "gerentes dão alto valor às fontes primárias devido à sua exclusividade e à provável vantagem competitiva que essa informação poderá proporcionar" e "as fontes secundárias proporcionam informações de bastidores capazes de sustentar as sugestões obtidas a partir das fontes primárias". Em qualquer fonte utilizada, é importante escolher o processo de coleta mais adequado e os modelos analíticos para garantir a eficácia dessa fase.

O processo de geração de inteligência parte da transformação de dados e informações esparsas em inteligência significativa para os tomadores de decisão. Nesta fase, podem ser utilizadas pesquisas científicas que garantam maior confiabilidade ao processo e softwares especializados, além de modelos estatísticos que demonstrem as relações existentes entre as variáveis e os padrões e tendências levantados. Esse processo exige, dentre outras habilidades e competências, persistência, criatividade e capacidade do profissional de IC de saber quando encerrar a análise (MILLER, 2002).

Após o processo de transformação de dados em informações e destas em inteligência, o próximo passo é a distribuição da inteligência aos centros de decisão. Nesta fase, os profissionais de IC devem estar atentos às necessidades dos tomadores de decisão e de como eles desejam que a inteligência processada lhes seja apresentada. É muito comum a apresentação em reuniões de equipe, via relatórios formais ou através de redes internas, como as intranets. Entender de que maneira os responsáveis pelas decisões preferem conhecer inteligências aumenta a integridade e a futura utilização do que é relatado (MILLER, 2002). Em síntese, o que importa é que a inteligência gerada seja repassada de maneira eficaz e no momento certo aos que precisam dela.

Miller (2002) ainda discute a importância das habilidades de outros profissionais para a expansão da função de inteligência. Ele aponta cinco tipos de profissionais. $\mathrm{O}$ primeiro deles, os "construtores" de dados, são aqueles responsáveis pelos processos de coleta, organização e disponibilização de imensos conjuntos de informações textuais ou gráficas de fontes internas e externas. Ao segundo tipo de profissional, o autor chama de "construtores" de sistema, profissionais responsáveis pelo fornecimento de tecnologias e serviços necessários para acessar, distribuir produtos e serviços de inteligência em toda a empresa. O terceiro refere-se ao pessoal da segurança com a função de proteger as estruturas e sistemas de dados contra acesso e utilização inadequados por pessoas não autorizadas, dentro e fora da empresa. O quarto profissional que ajuda a desenvolver e a expandir os processos de IC são aqueles ligados à área jurídica da empresa que assegura a utilização dos métodos adequados para o exercício da inteligência. E, finalmente, o autor chama de "construtores" do conhecimento tanto da academia quanto da comunidade empresarial os profissionais que pesquisam novos limites e modelos para a gestão cada vez mais eficaz da função de inteligência (MILLER, 2002).

Trabalhar com inteligência requer uma estrutura adequada de processos e de profissionais que sejam capazes de fornecer os insights necessários para que a organização mantenha um crescimento sustentável em seu mercado competitivo ao longo do tempo. Não é preciso criar estruturas fantásticas para iniciar um processo de IC, mas é de suma importância ter profissionais qualificados e competentes envolvidos nas quatro fases até aqui apresentadas.

Como se analisou até agora, a literatura define o termo inteligência competitiva (IC) de diversas maneiras, mas em todas elas percebe-se a presença de quatro processos fundamentais: (1) o processo de planejamento levantamento das necessidades de informações e os decisores-chave; (2) o processo de coleta de dados; (3) o processo da análise dos dados, transformando-os em informações e, posteriormente, em inteligência; (4) o processo de disseminação da inteligência gerada aos responsáveis pelo processo de tomada de decisão organizacional. A Society of Competitive Intelligence Professinals (SCIP,2007) complementa essa definição com a questão ética no processo de coleta de dados. Para essa entidade, não se pode confundir as práticas de IC com espionagem, uma vez que uma boa prática de IC tem de ser, além de ética, legal. A figura 1, a seguir, ilustra a estrutura de IC com os seus processos fundamentais discutidos até o presente momento.

Após a análise das considerações acima, pode-se inferir as seguintes conclusões sobre a prática de IC: (a) 
FIGURA 1

O ciclo de IC no contexto organizacional e competitivo

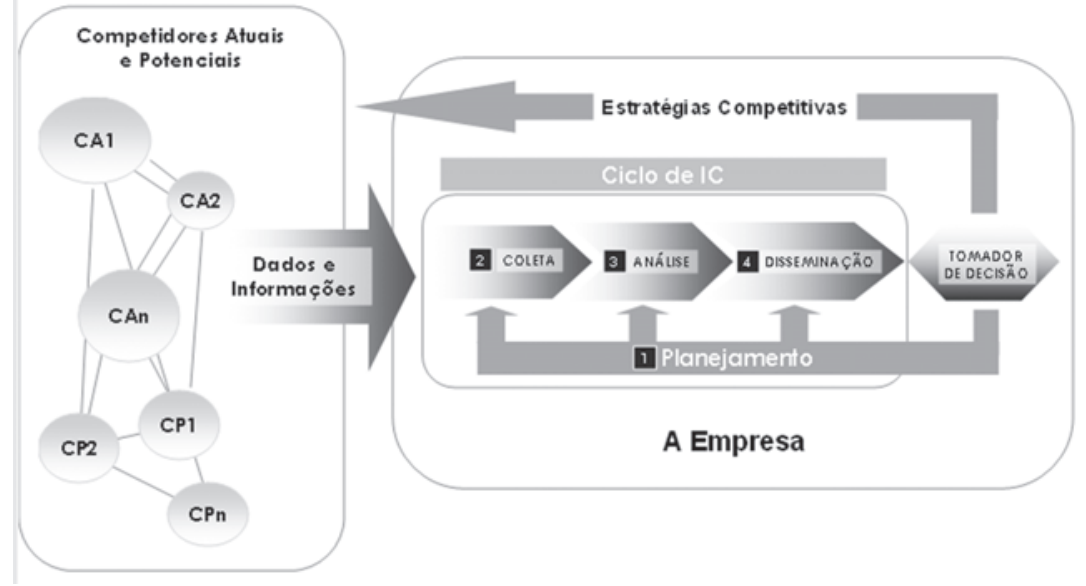

Fonte: autor da pesquisa.

normalmente, é um processo formal e sistematizado; (b) atua como um processo de monitoração contínuo do ambiente de negócios; (c) apresenta um ciclo de atividades que vai desde o planejamento até o processo de disseminação de inteligência aos responsáveis pela tomada de decisão; (d) é orientado para o futuro, buscando antever as mudanças do mercado e dos concorrentes; (e) precisa de uma adequada infra-estrutura de TI e de profissionais de inteligência com habilidades e competências diferenciadas; (f) é um processo que se fundamenta nos valores éticos e legais, não se confundindo com espionagem.

\section{PROFISSIONAIS DE IC: HABILIDADES E COMPETÊNCIAS}

Habilidades e competências têm sido estudadas por diversos especialistas e gerado diversas definições e entendimentos (BRANDÃO; GUIMARÃES, 2001). Para esse estudo, foram utilizadas as definições do Instituto Nacional de Estudos e Pesquisas Educacionais Anísio Teixeira (INEP, 2007), que entende o termo "competência" como "modalidades estruturais da inteligência, ou melhor, ações e operações que utilizamos para estabelecer relações com e entre objetos, situações, fenômenos e pessoas que desejamos conhecer" e o termo "habilidade" por "competências adquiridas e referem-se ao plano imediato do saber fazer".

Em suas pesquisas, Katz (1974) classifica as habilidades necessárias a um profissional de gestão em três grupos principais. Para ele, um profissional que atua com as funções de gerenciamento deve desenvolver a habilidade conceitual, caracterizada como a capacidade cognitiva de entender e visualizar a organização como um sistema e as inter-relações existentes entre as suas partes. Essa visão sistêmica da organização é compartilhada por muitos teóricos, dentre eles Bertalanffy (1976) e Morgan (1996), que usam os conceitos e as configurações de sistemas e de subsistemas para descrever padrões-chave de interconexões entre as diversas unidades organizacionais. Da mesma forma que os organismos, é possível conceber as organizações como subsistemas e definir esses subsistemas de muitas maneiras diferentes (MORGAN, 1996).

Outro aspecto apresentado por Katz refere-se à habilidade humana, ou seja, a capacidade do profissional de trabalhar com e entre as outras pessoas de maneira eficaz, como membros de um grupo. Essa habilidade trata, dentre outras coisas, da capacidade de comunicação, liderança, motivação e de trabalho em equipe (ou times) por parte dos gestores organizacionais. E, por fim, a habilidade técnica, que se refere ao entendimento e proficiência no desempenho de tarefas específicas. Ela normalmente inclui o domínio dos métodos, das técnicas e dos equipamentos que envolvem funções específicas realizadas pela empresa e os conhecimentos especializados, capacidade analítica e o uso competente de instrumentos e técnicas de resolução de problemas em determinada área (DAFT, 1999).

Vargas e Souza (2001, p. 9 -13) abordam as atividades dos profissionais de IC a partir de quatro grupos de atividades principais. No grupo, estão as atividades estratégicas, relacionadas com visão holística da empresa; do seu ambiente concorrencial, bem como os fatores críticos de sucesso. No segundo, estão as atividades gerenciais ligadas diretamente com a direção, a tomada de decisões, a supervisão e o controle das atividades de IC. O terceiro grupo refere-se às atividades técnicas, que estão diretamente relacionadas com o uso de métodos, de tecnologias da informação e de processos específicos de trabalho, como a identificação de fontes de dados e informações e o uso de aplicativos especializados para as práticas de IC. No quarto e último grupo, estão as habilidades humanas, caracterizadas pela capacidade de os profissionais de IC se inter-relacionarem com as demais pessoas da organização. Vargas e Souza (2001:12)

consideram a motivação, a comunicação eficaz com as pessoas participantes de uma equipe, o compartilhamento de informações, o suporte à aprendizagem do grupo como um conjunto de atividades humanas. 
Miller (2002) descreve algumas habilidades e competências necessárias para os profissionais que trabalham com inteligência competitiva. $\mathrm{O}$ autor discute essas qualificações tomando como base as etapas do ciclo de IC, conforme analisado anteriormente. Para ele, o perfil dos profissionais de IC tem evoluído nos últimos anos, e a globalização e o avanço tecnológico ocorrido nas últimas décadas têm delineado um cenário desafiador para as organizações nesse início de milênio e demandado cada vez mais profissionais de IC com qualificações multidisciplinares e habilidades multifuncionais e sistêmicas nesta era da economia da informação, como afirma Borges (1995, p.3):

A economia da informação produzirá um número extraordinário de empregos desafiadores, que exigem um alto grau de competência, com capacidade de pensar criticamente, de planejar estrategicamente e de se adaptar a mudanças.

Atualmente, percebe-se uma necessidade crescente de atualização profissional em todos os tipos de carreiras. No caso específico dos profissionais de IC, que lidam diariamente com dados e informações sobre o ambiente competitivo, cada vez mais dinâmico e imprevisível, o treinamento e o desenvolvimento em habilidades e competências devem estar voltados para os temas relevantes ao processo de IC, como, por exemplo, para o pensamento estratégico, as terminologias de negócios, as pesquisas de mercado, as técnicas de apresentação, o conhecimento aprofundado sobre fontes primárias e secundárias de informação, a metodologia de pesquisa, as técnicas de entrevistas, as técnicas de comunicação e a capacidade de análise e síntese, dentre outras competências e habilidades. O desenvolvimento dessas competências tem se tornado, no atual contexto competitivo, fator preponderante para o sucesso na carreira em IC e para o êxito dos processos e sistemas de IC.

Miller (2002) ainda aponta algumas características pessoais e a experiência como fatores importantíssimos que devem ser considerados para os atuais e

\section{QUADRO 2} Prescott e Miller (2002). futuros profissionais de IC. Para ele, a criatividade, a persistência, as habilidades pessoais (relacionamento), uma mente analítica (análise e síntese de conhecimentos), a astúcia para os negócios e a capacidade de aprender sozinho, além da grande experiência profissional, conhecimento pleno do setor em que a empresa está inserida e o entendimento das estruturas e processos decisórios da organização, têm incentivado muitas entidades de ensino, como a Universidade Federal de Minas Gerais (UFMG), pela Escola de Ciência da Informação, a Universidade Federal de Santa Catarina (UFSC), o Instituto Brasileiro de Informação em Ciência e Tecnologia (Ibict) e associações profissionais, como a Society of Competitive Intelligence Professionals (SCIP) nos Estados Unidos e a Associação Brasileira de Inteligência Competitiva (Abraic), no Brasil, a criar cursos e programas específicos para o aperfeiçoamento desses profissionais que emergem em um mundo em constante transformação, o qual exige profissionais cada vez mais qualificados e que dêem respostas satisfatórias aos problemas e aspirações organizacionais (MILLER, 2002).

O quadro 2 foi construído para facilitar a visualização das habilidades e competências desejadas aos profissionais de IC nos diferentes estágios do ciclo de inteligência, conforme pesquisa bibliográfica realizada.

Principais habilidades e competências desejadas aos profissionais de IC nos diferentes estágios do Ciclo de IC

\begin{tabular}{|c|c|c|c|c|c|}
\hline \multirow[t]{2}{*}{ Habilidades } & \multirow[t]{2}{*}{ Tipos } & \multicolumn{4}{|c|}{$\begin{array}{l}\text { Fases do Ciclo de } \\
\text { IC }\end{array}$} \\
\hline & & $\mathbf{P}$ & C & A & D \\
\hline \multirow{8}{*}{ Humanas } & Astúcia & (;) & (-) & (;) & \\
\hline & Comunicação & () & (2) & (2) & (2) \\
\hline & Perspicácia & (-) & (:) & (:) & \\
\hline & Criatividade & ()) & ()) & (:) & (:) \\
\hline & Persistência & & (2) & (:) & \\
\hline & Intuição & (2) & (2) & (2) & \\
\hline & Autodidata (capacidade de aprendizado autônoma) & (2) & (2) & (2) & \\
\hline & Confiabilidade & ()) & (-) & (-) & (;) \\
\hline \multirow{6}{*}{ Técnicas } & Capacidade de coleta de dados & & (:) & & \\
\hline & Conhecimento de fontes de informações & (;) & (:) & & \\
\hline & Conhecimento em metodologia científica & & & (;) & \\
\hline & Capacidade de pensar estrategicamente & (;) & & (:) & \\
\hline & Conhecimento em ferramentas análises de IC & & & (-) & \\
\hline & Habilidade de pesquisa & & (:) & (;) & \\
\hline \multirow{6}{*}{ Conceituais } & Conhecimento sobre o setor industrial & ()) & (:) & (-) & \\
\hline & Conhecimento das estruturas de poder da organização & (:) & & (:) & (;) \\
\hline & Conhecimento sobre os processos de tomada de decisão & (;) & & (-) & \\
\hline & Conhecimento das forças do mercado que influenciam a empresa & (;) & & ()) & \\
\hline & Compreensão da cultura organizacional & (:) & & (:) & (:) \\
\hline & Conhecimento das preferências dos administradores & (2) & & (2) & (2) \\
\hline
\end{tabular}

Fonte: Tyson (1998) apud Tarapanoff(2001), Starec et al. (2006), Bernhardt (2004), Miller (2002) e 
$\mathrm{O}$ quadro 2 busca classificar as principais habilidades e competências desejáveis aos profissionais de IC encontradas na literatura a partir das fases do ciclo de IC. Para tanto, utilizaram-se os estudos de Katz (1974) sobre habilidades e competências do administrador efetivo, que forneceu uma estrutura de classificação a partir das habilidades gerais, chamadas por ele de habilidades humanas, técnicas e conceituais, e os estudos de autores como Starec et al. (2006), Bernhardt (2004), Gomes e Braga (2004), Miller (2002), Prescott e Miller (2002) e Tarapanoff (2001), dentre outros. A construção desse quadro permitiu reunir as habilidades e competências dos profissionais de IC em três grandes grupos de habilidades. Nota-se que, neste exemplo, a habilidade técnica está sendo utilizada como sinônimo de competência, ou seja, saber fazer.

Analisando-se as habilidades e competências e as respectivas fases do ciclo da IC, percebe-se que a capacidade de aprendizado autônomo do profissional de IC, a sua confiabilidade perante os demais membros da organização e o conhecimento das forças do mercado que influenciam a empresa, além da sua capacidade de comunicação, são fatores que aparecem em quase todas as fases do ciclo de IC. Isso se justifica pela necessidade de profissionais éticos, proativos e dinâmicos, diante de um ambiente em constante transformação.

$\mathrm{Na}$ fase de planejamento (P), as habilidades humanas referentes à astúcia, comunicação, perspicácia, criatividade, capacidade de aprendizado (autodidata) e confiabilidade assumem grande relevância, uma vez que os profissionais de IC devem interagir com os responsáveis pelo processo decisório, trocando informações sobre as necessidades de inteligência e os produtos de inteligência a serem disponibilizados em tempo oportuno. Já na fase de coleta (C), além de algumas dessas habilidades, outras duas se destacam: a persistência e a intuição. Para a coleta de dados e informações de qualidade, muitas vezes os profissionais de IC devem persistir na busca por fontes primárias e/ou secundárias mais confiáveis, que forneçam as informações necessárias para posterior análise e geração de inteligência útil para a organização. Também, em algumas vezes, devem se valer da intuição, à medida que se torna difícil a obtenção das informações mais acuradas em situações. $\mathrm{O}$ uso de analogias pode ajudar os profissionais de IC a criar soluções criativas em determinadas situações adversas e imprevisíveis.

Em contrapartida, na fase de análise (A), as habilidades humanas que se destacam são as ligadas à capacidade criativa e à perspicácia. Para um processo de análise produtivo e eficaz, torna-se necessário que o profissional aprofunde ao máximo nos dados e informações coletadas mediante postura sagaz e compreensiva dos fatos, revelando os seus meandros e as interações existentes entre elas e respectivos impactos sobre a organização; condições necessárias para se abstrair a inteligência útil para o processo decisório. Finalmente, na fase de disseminação (D), pela sua natureza de interação, as habilidades humanas que mais se destacam referem-se à capacidade comunicativa e criativa ao objetivar a inteligência gerada em métodos de transmissão oral, escrita, visual ou digital da inteligência, como relatórios, intranets, reuniões, painéis, entre outros, e à sua confiabilidade perante os demais membros da organização. Criar boa reputação interna, pautada na ética, competência, qualidade e confiança pode ajudar os profissionais de IC a desenvolver com maior eficiência e eficácia suas atividades.

Quando se abordam as habilidades técnicas necessárias aos profissionais de IC, cada fase do ciclo de IC naturalmente demanda algumas habilidades específicas. Por exemplo, na fase de coleta de dados e de informações, é necessário selecionar eficazmente as melhores fontes de informações, aquelas que forneçam a qualidade necessária para que o processo de geração de inteligência competitiva transcorra da melhor forma possível. É importante também que nesta fase o profissional conheça as ferramentas adequadas da tecnologia da informação (TI), uma vez que o mesmo pode trabalhar com a necessidade de armazenar e de processar grandes volumes de dados e informações. Já na fase seguinte - análise dos dados e informações para a geração de inteligência útil - é importante que os profissionais de IC tenham a capacidade de pensamento estratégico, conheçam sobre metodologia científica e dominem as principais ferramentas para análise de IC, como análise SWOT, modelo de "5 Forças" de Porter Benchmarking, dentre outras.

E, por fim, é importante que os profissionais desenvolvam as suas habilidades conceituais, ou seja, ter conhecimento sistêmico da organização, saber enxergar as ameaças e oportunidades do ambiente, além de reconhecer os pontos fortes e fracos da organização. $\mathrm{Na}$ fase de planejamento e coleta, apresentem conhecimentos sobre o setor industrial no qual a organização está inserida, sobre a estrutura de poder da organização, dos processos de tomada de decisão e da sua cultura e preferências dos administradores e usuários dos produtos de inteligência. Conhecer as forças do mercado que influenciam a empresa também se configura em habilidade essencial, principalmente, na fase de análise do ciclo de IC. Finalmente, na fase de disseminação da inteligência produzida, além de muitas dessas habilidades e 
competências mencionadas, é coveniente que o profissional de IC conheça os processos de decisão e as preferências do administrador, uma vez que eles estarão em contato direto com os usuários da inteligência.

\section{CONSIDERAÇÕES FINAIS}

É certo que o terceiro milênio configurará um novo tempo para as organizações e para os profissionais de IC. Eles enfrentarão ambientes cada vez mais complexos, dinâmicos e imprevisíveis. Entra-se numa época marcada por incertezas e pelo aumento da complexidade ambiental, caracterizada pelo aumento da pressão por parte dos consumidores, competidores, fornecedores, investidores, governos e pela sociedade em geral. Como conseqüência, percebe-se crescente necessidade dos gestores por informações cada vez mais confiáveis, rápidas e consistentes que lhes forneçam o conhecimento e a inteligência necessária para um processo de tomada de decisão eficiente e eficaz.

Para muitos profissionais de IC, este início de século tem oferecido grandes desafios e oportunidades. Um dos mais importantes refere-se à sua capacidade de adaptação às novas condições de trabalho. Entenda-se por adaptação a capacidade que o indivíduo tem de se ajustar, com eficiência e eficácia, ao contexto produtivo no qual está inserido, criando estratégias para minimizar, neutralizar ou antever as ameaças e prover as condições necessárias para o aproveitamento de oportunidades de trabalho que venham a surgir neste ambiente em constante transformação. Assim, para "garantir" um processo de ajuste eficiente e eficaz, os profissionais de IC devem se preocupar em manter e desenvolver habilidades e competências diferenciadas e úteis para as organizações, que têm precisado, cada vez mais, de dados e informações seguras e precisas sobre o seu ambiente competitivo, para que o processo de planejamento estratégico desenvolva as medidas necessárias à neutralização (ou minimização) dos impactos causados pelo aumento da incerteza ambiental sobre a organização e a geração de vantagens competitivas sustentáveis e duradouras nos mercados competitivos onde atuam.

A necessidade de mudança constante reforça a importância de manter um processo de inteligência competitiva adequado às necessidades organizacionais, potencializando o seu processo decisório. Desta forma, percebe-se que o crescimento da concorrência em quase todos os setores da economia parece ser a força propulsora que impulsiona as empresas a investirem cada vez mais na expansão das suas áreas de IC e na qualificação de seus profissionais, como demonstrado pela pesquisa realizada pela Global Intelligence Alliance (2007) e pela pesquisa realizada por Vargas e Souza (2001) e Miller (2002).

Outro dado importante revelado por esse estudo é o de que as habilidades e competências tendem a variar conforme as fases constantes do ciclo de IC. Na fase inicial de planejamento, as habilidades humanas e conceituais parecem ser as que mais se destacam. Essa constatação decorre da natureza integrativa e sistêmica dessa fase. Se existe um contato direto dos profissionais de IC com os usuários da inteligência a ser produzida, também existe uma demanda por conhecimentos holísticos e sistêmicos da organização, como; por exemplo, conhecimentos sobre ambiente competitivo (setor industrial); estrutura de poder da organização; processo decisório; cultura organizacional e preferências dos administradores. Nas demais fases do ciclo de IC, percebe-se equilíbrio existente entre as demais habilidades (humanas, técnicas e conceituais). $O$ interessante a se destacar é a grande importância dada às habilidades referentes à capacidade de aprendizagem, perspicácia, criatividade, confiabilidade e conhecimentos sobre as forças do mercado que influenciam a empresa. É prudente observar que estes resultados derivam de uma revisão de bibliografia a partir da análise de obras de diversos autores situados em diferentes países e contextos históricos. Para uma conclusão mais realista e abrangente, torna-se necessário realizar estudos mais aprofundados sobre o tema em questão.

Em síntese, este artigo analisou as habilidades e competências desejáveis aos profissionais de IC nesse início de século a partir de uma cuidadosa revisão de literatura. Foram utilizados os estudos de Katz (1974) sobre as habilidades humanas, técnicas e conceituais a serem desenvolvidas e adaptadas pelos profissionais de IC para uma consecução efetiva de suas atividades de inteligência. Este estudo revelou um conjunto de habilidades e competências desejáveis, ao longo do ciclo de IC, para que esses profissionais desenvolvam suas atividades de geração e distribuição de inteligência com maior eficiência e eficácia, além da possibilidade de obterem melhores oportunidades de trabalho nesse mercado em plena expansão. Assim, percebe-se que o crescimento da concorrência em todos os setores da economia tem demandado profissionais de IC cada vez mais qualificados e gerado um campo de oportunidades e número extraordinário de trabalhos (e empregos) desafiadores. Tudo isso exige profissionais com habilidades e competências multifuncionais e multidisciplinares, fundamentadas no pensamento crítico, no planejamento estratégico e nos métodos e técnicas de análise de IC (BORGES, 1995). 
Artigo submetido em 07/09/2007 e aceito em 17/04/2008.

\section{REFERENNCIAS}

ASSOCIAÇÃO BRASILEIRA DOS ANALISTAS DE INTELIGÊNCIA COMPETITIVA - ABRAIC. Disponível em: < www.abraic.org.br > . Acesso em: 20 ago. 2008.

BERTALANFFY, L. Teoria geral de sistemas. Petrópolis: Vozes, 1976.

BRANDÃO, H. P.; GUIMARÃES, T. A. Gestão de competências e gestão de desempenho: tecnologias distintas ou instrumentos de um mesmo constructo?. Revista de Administração de Empresas, v. 41, n. 1, p. 8-15, jan./mar. 2001.

BERNHARDT, D. Competitive intelligence: how to acquire and use corporate intelligence and counter-intelligence. London: Prentice Hall, 2004.

BORGES, M.E.N. A informação como recurso gerencial das organizações na sociedade do conhecimento. Ciência da Informação, v. 24, n. 2, 1995.

CHOO, C. W. A organização do conhecimento: como as organizações usam a informação para criar significado, construir conhecimento e tomar decisões. São Paulo: Senac, 2003. 425 p.

DAFT, R. L. Organizações: teorias e projetos. 7. ed. São Paulo: Pioneira Thomson Learning, 2002. 532 p.

D’AVENI, R. A. Hipercompetição: estratégias para dominar a dinâmica do mercado. Rio de Janeiro, 1995.460 p.

FULD, L. M. The new competitor intelligence: the complete resource for finding, analyzing, and using information about your competitors. New York: John Wiley \& Sons, $1995.512 \mathrm{p}$.

HOPE, J; HOPE, T. Competindo na terceira onda: os 10 mandamentos da era da informação. Rio de Janeiro: Campus, 2000. 302 p.

GOMES, E; BRAGA, F. Inteligência competitiva: como transformar informação em um negócio lucrativo. Rio de Janeiro: Campus, 2004. 144 p.

GLOBAL INTELLIGENCE ALLIANCE. Global intelligence alliance releases 2007: study on market intelligence in large companies. Disponível em: $<\underline{\text { http:/ }}$ Lwww.globalintelligence.com/news/news/latest/ 22052007 >. Acesso em: 03 set. 2007.

INSTITUTO NACIONAL DE ESTUDOS E PESQUISAS EDUCACIONAIS ANÍSIO TEIXEIRA INEP. Competências e habilidades. Disponível em: $<\underline{\text { http:// }}$ www.enem.inep.gov.br>. Acesso em: 01 set. 2007.

KAHANER, L. Competitive Intelligence: how to gather, analyse and use information to move your business to top. New York: Touchstone, 1996. 300 p.

KATZ, R. L. Skills of an effective administrator. Harvard Business Review, n. 52, p. 90-102, Sept./Oct. 1974.

MILLER, J. P. O nascimento e o crescimento do seu processo de inteligência: fatores comportamentais, culturais e estruturais. In: MILLER, J. P. (Org.). O milênio da inteligência competitiva. São Paulo: Bookman, 2002. p. 53-65.

MORGAN, Gareth. Imagens da organização. São Paulo: Atlas, 1996.424 p.

PORTER, M. E. Competitive advantage: creating and sustaining competitive performance. New York: Free Press, 1998. 592 p.

PRESCOTT, J; MILLER, S. Inteligência competitiva na prática. Rio de Janeiro: Campus, 2002.

SOCIETY OF COMPETITIVE INTELLIGENCE PROFESSIONALS - SCIP. Disponível em: < www.scip.org > Acesso em: 16 jul. 2007.

STAREC, C; GOMES, E. B. P; BEZERRA, J. (Org.). Gestão estratégica da informação e inteligência competitiva. São Paulo: Saraiva, 2005. 351 p.

TARAPANOFF, Kira (Org.). Inteligência organizacionale competitiva. Brasília: Editora da UnB, 2001.344 p.

TYSON, K. W. M. The complete guide to competitive intelligence. In: TARAPANOFF, Kira (Org.). Inteligência organizacional e competitiva. Brasília: Editora da UnB, 2001.

VARGAS, L. M.; SOUZA, R. F. O ator de inteligência competitiva (IC) nas empresas: habilidades profissionais e exigências do mercado. REAd, v. 7, n. 6, nov./dez. 2001. Edição especial. 